\title{
Seasonal variability in the response of ground beetles (Coleoptera: Carabidae) to a forest edge in a heterogeneous agricultural landscape in Japan
}

\author{
Atsushi OHWAKI ${ }^{1}$, Yohei KANEKO ${ }^{1, *}$ and Hiroshi IKEDA ${ }^{2}$ \\ ${ }^{1}$ Center for Toki \& Ecological Restoration, Niigata University, 1101-1, Niibokatagami, Sado 952-0103, Japan; \\ e-mail: papiho@hotmail.co.jp \\ ${ }^{2}$ Faculty of Agriculture and Life Science, Hirosaki University, 3, Bunkyocho, Hirosaki 036-8561, Japan; \\ e-mail: hikeda@cc.hirosaki-u.ac.jp
}

Key words. Coleoptera, Carabidae, boundary, edge effect, edge response, seasonality, temperate region

\begin{abstract}
Understanding arthropod responses to forest edges is essential to understanding both the characteristics of agro-ecosystems and the potential ecosystem services provided by forests adjacent to farmland in heterogeneous agricultural landscapes. Seasonal difference in the responses of carabid beetles to forest edges was determined using transects that extended from the edge of the forest $22.5 \mathrm{~m}$ into the interior of a forest and $22.5 \mathrm{~m}$ into the meadow in three seasons, early summer, late summer and mid-autumn. The responses of carabids to the forest edge in terms of species richness and abundance differed significantly in the three seasons. The species richness and abundance peaked in the meadow $4.5 \mathrm{~m}$ from the edge and were low in the forest in summer, whereas they peaked at the edge and remained high in the forest in autumn. Species-level analyses revealed that several species did not move between habitats, indicating that the forest edge acted as a barrier for these species. Many species, however, peaked in the meadow near the edge and the distribution of one species along the meadow-forest transect changed with the seasons. Our results indicate that secondary forests are not an effective sources of predators of pests, but do function as overwintering sites for some species. Because many species that prefer open land hibernate in field boundaries and fallow fields, the quality and spatial configuration of these habitats is important. Furthermore, in terms of pest management the seasonal dynamics of not only carabid beetles but other beneficial arthropods such as spiders and parasitoids should be considered.
\end{abstract}

\section{INTRODUCTION}

Landscape heterogeneity is a key feature determining biodiversity in agricultural landscapes (Weibull et al., 2000; Kato, 2001; Benton et al., 2003). Secondary forests and farmlands are often dominant and complicatedly arranged in a mosaic manner in agricultural landscapes in East Asia (Kato, 2001; Kim et al., 2006) and Europe (Bergman et al., 2004; Falcucci et al., 2007). In this landscape there are a large number of boundaries between secondary forests and farmland, which are referred to as "forest edges". Seminatural vegetation, such as secondary forest and grassland, is currently recognized as a source of agents of pollination and predators of pests, such as insect pollinators, predatory arthropods, and parasitoids (Thies et al., 1999; Kremen et al., 2002, 2004). Therefore, information on the responses of arthropods to forest edges is essential not only for understanding the characteristics of agro-ecosystems (Rand et al., 2006; van Halder et al., 2011) but also for evaluating the ecosystem services that forest ecosystems may provide adjacent farmland in such heterogeneous agricultural landscapes.

Forest edges differ from forest interiors and adjacent open land in terms of temperature, humidity, light conditions and vegetation structure (Matlack, 1993; Murcia, 1995) and the responses of arthropods to forest edges are explained in terms of the distribution of resources (Ries \&
Sisk, 2004; Ries et al., 2004). The gradient or contrast in these environmental conditions across a forest edge, however, differs between seasons (Ries et al., 2004). For example, the gradient in air temperature and humidity across a forest-pasture edge is steeper in summer than winter (Young \& Mitchell, 1994). Given the expected seasonal changes in environmental conditions and distributions of resources across a forest edge, arthropod responses to forest edges may differ between seasons. However, most studies of arthropods' responses to forest edges have used pooled data from different seasons, and seasonal differences in arthropods' responses to edges are poorly studied (French et al., 2001; Barbosa \& Marquet, 2002). Therefore, to understand ecological interactions between adjacent habitats, seasonal changes in the responses to forest edges should be investigated at species and community levels.

We determined the responses of carabid beetles to a forest edge in three seasons. Carabid beetles play important roles in many ecosystems as generalist predators and seed predators, and are often very abundant in various types of vegetation (Lövei \& Sunderland, 1996; Kromp, 1999). These characteristics make them potentially important agents of pest and weed control in agro-ecosystems (Lövei \& Sunderland, 1996; Honek et a., 2007; Ichihara et al., 2011; Yamashita, 2011), but a number of species are pests that damage crops such as radish (Mizukoshi, 2000). Furthermore, because they are easily collected using pitfall

\footnotetext{
* Present address: Fukuoka Institute of Health and Environmental Sciences, 39, Mukaizano, Dazaifu 818-0135, Japan; e-mail: kaneko@fihes.pref.fukuoka.jp
} 

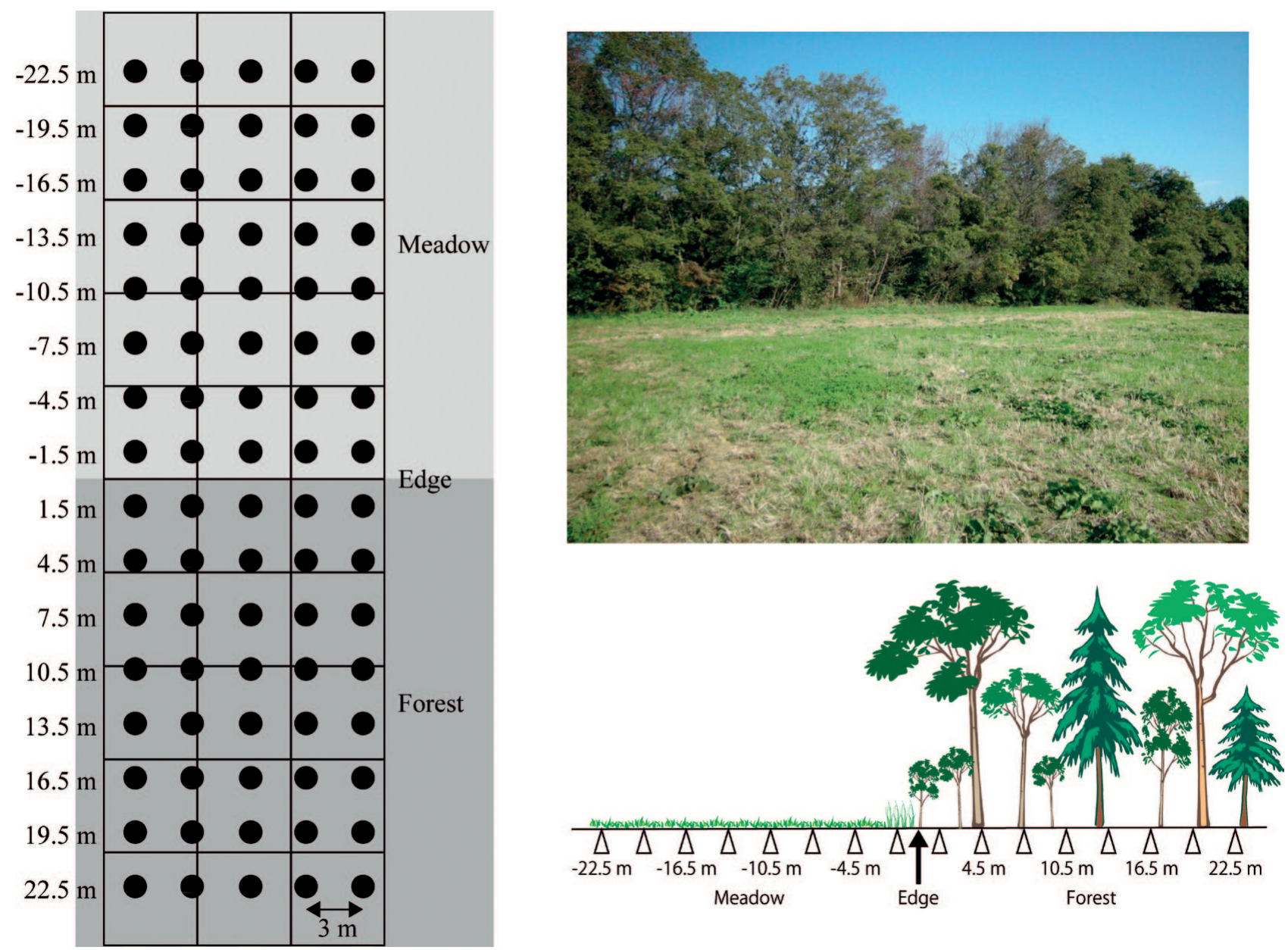

Fig. 1. Locations of the pitfall traps along transect (left), photograph (upper right) and schematic profile (bottom right) of the study site. In the figure on the left, black dots and squares indicate the position of the pitfall traps and subquadrats where vegetation was surveyed, respectively.

traps, the spatial distribution and activity density of beetles can be determined using a spatial arrangement of traps suited to the desired research aims.

In this study, we determined the response of carabid beetles to forest edges and whether their responses varied between seasons at a fine scale in a temperate farmlandforest mosaic agricultural landscape. Some insects such as butterflies change their micro-distribution seasonally for purposes of thermoregulation. For example, forest butterflies move into the warm and sunny edges of forests in cool seasons (Ide, 2002), whereas species preferring open land move into cool and shady areas in hot summer (Ohsaki, 1986). The activity of carabid beetles also changes with temperature (Honek, 1997). Therefore, we hypothesized that richness and abundance of carabid beetles would peak in the edges of forests in hot summer due to the movement of species preferring open land into the forest to avoid high temperatures, whereas they would peak in the edges of open land due to the movement of forest species or edge species into the open land in early summer and autumn, when temperatures are moderate. Furthermore, we performed species-level analyses to determine how species that prefer forest, edge or open land co-exist in a mosaic landscape.

\section{MATERIAL AND METHODS}

\section{Study site}

The study site is located in the northeast of the Kuninaka Plain at an altitude of $15 \mathrm{~m}$ on Sado Island in temperate Japan $\left(38^{\circ} 03^{\prime} \mathrm{N}, 138^{\circ} 26^{\prime} \mathrm{E}\right)$ and is composed of a mosaic landscape of secondary deciduous oak forests, plantations of Japanese cedar Cryptomeria japonica, paddy fields and hay meadows where seed of orchard grass Dactylis glomerata and Italian ryegrass Lolium multiflorum is sown every three to four years and chemical fertilizer and cow urine applied twice and once a year, respectively. Within this landscape, one $15 \mathrm{~m} \times 50 \mathrm{~m}$ quadrat was established, which stretched for $25 \mathrm{~m}$ in both directions from the edge of a forest into the interior of both the forest and a meadow. The edge was high-contrast (Fig. 1), which is common in agricultural landscapes (Roume et al., 2011), and south-southeast facing. The forest edge was here defined as a growing frontier of shruby trees, with branches of canopy trees extending 4-5 $\mathrm{m}$ into the meadow (Fig. 1). The canopy of the forest was dominated by Quercus serrata, Prunus jamasakura and planted Japanese cedar $(<6 \mathrm{~m})$, with a canopy height of $14 \mathrm{~m}$. Management, such as coppicing and maintenance of the Japanese cedar, seemed to have ceased approximately 20-30 years previously. The meadow was mown three times a year (mid-June, mid-August and mid-October) to a height of $10-\mathrm{cm}$ when the vegetation reached approximately 70 $\mathrm{cm}$ and the hay collected and fed to cows. The meadow was dominated by Echinochloa crus-galli, Rumex japonicas, Digitaria 
TABLE 1. A list of carabid beetles caught in the pitfall traps along with their feeding habits and the number caught. C - carnivore, $\mathrm{G}$ - granivore, $\mathrm{U}$ - unknown, $\mathrm{F}$ - the number caught in the forest, $\mathrm{M}$ - the number caught in the meadow.

\begin{tabular}{|c|c|c|c|c|c|c|c|}
\hline \multirow{2}{*}{ Species } & \multirow{2}{*}{ Feeding habit } & \multicolumn{2}{|c|}{ Early summer } & \multicolumn{2}{|c|}{ Late summer } & \multicolumn{2}{|c|}{ Autumn } \\
\hline & & $\mathrm{F}$ & $\mathrm{M}$ & $\mathrm{F}$ & $\mathrm{M}$ & $\mathrm{F}$ & $\mathrm{M}$ \\
\hline Carabus albrechti Morawitz & $\mathrm{C}$ & 0 & 0 & 7 & 0 & 0 & 0 \\
\hline Carabus insulicola Chaudoir & $\mathrm{C}$ & 0 & 1 & 1 & 0 & 0 & 1 \\
\hline Archipatrobus flavipes (Motschulsky) & $\mathrm{C}$ & 0 & 1 & 0 & 0 & 0 & 1 \\
\hline Pterostichus planicollis (Motschulsky) & $\mathrm{C}$ & 0 & 31 & 0 & 38 & 0 & 5 \\
\hline Pterostichus sulcitarsis Morawitz & $\mathrm{C}$ & 0 & 3 & 0 & 8 & 0 & 0 \\
\hline Pterostichus haptoderoides japanensis Lutshnik & $\mathrm{C}$ & 0 & 0 & 0 & 0 & 0 & 1 \\
\hline Pterostichus noguchii Bates & $\mathrm{C}$ & 0 & 0 & 0 & 1 & 1 & 0 \\
\hline Pterostichus yoritomus Bates & $\mathrm{C}$ & 2 & 0 & 5 & 0 & 5 & 0 \\
\hline Pterostichus prolongatus Morawitz & $\mathrm{C}$ & 0 & 0 & 0 & 0 & 0 & 1 \\
\hline Pterostichus microcephalus (Motschulsky) & $\mathrm{C}$ & 26 & 7 & 2 & 8 & 22 & 7 \\
\hline Pterostichus polygenus Bates & $\mathrm{C}$ & 0 & 0 & 0 & 0 & 1 & 0 \\
\hline Platynus magnus (Bates) & $\mathrm{C}$ & 0 & 0 & 0 & 0 & 0 & 1 \\
\hline Platynus chalcomus (Bates) & $\mathrm{C}$ & 0 & 0 & 0 & 0 & 0 & 1 \\
\hline Platynus quadripunctatus (De Geer) & $\mathrm{C}$ & 0 & 1 & 0 & 0 & 0 & 0 \\
\hline Dolichus halensis (Schaller) & $\mathrm{C}$ & 0 & 0 & 0 & 7 & 0 & 7 \\
\hline Synuchus nitidus (Motschulsky) & $\mathrm{C}$ & 1 & 0 & 0 & 0 & 15 & 0 \\
\hline Synuchus cycloderus (Bates) & $\mathrm{C}$ & 2 & 0 & 0 & 0 & 6 & 0 \\
\hline Synuchus dulcigradus (Bates) & $\mathrm{C}$ & 2 & 0 & 0 & 0 & 2 & 0 \\
\hline Synuchus arcuaticollis (Motschulsky) & $\mathrm{C}$ & 1 & 0 & 0 & 0 & 3 & 0 \\
\hline Amara chalictes (Dejean) & G & 0 & 25 & 0 & 0 & 0 & 1 \\
\hline Anisodactylus signatus (Panzer) & G & 0 & 7 & 0 & 0 & 0 & 0 \\
\hline Anisodactylus punctatipennis Morawitz & G & 0 & 7 & 0 & 1 & 0 & 1 \\
\hline Anisodactylus sadoensis Schauberger & G & 1 & 7 & 0 & 0 & 0 & 0 \\
\hline Harpalus vicarius Harold & G & 0 & 0 & 0 & 0 & 1 & 1 \\
\hline Harpalus jureceki (Jedlicka) & G & 0 & 0 & 0 & 2 & 0 & 2 \\
\hline Harpalus sinicus Hope & G & 0 & 0 & 0 & 13 & 2 & 1 \\
\hline Oxycentrus argutoroides (Bates) & $\mathrm{U}$ & 0 & 0 & 0 & 2 & 0 & 0 \\
\hline Epomis nigricans (Wiedemann) & $\mathrm{C}$ & 0 & 0 & 0 & 0 & 1 & 0 \\
\hline Chlaenius pallipes Gebler & $\mathrm{C}$ & 4 & 39 & 1 & 32 & 0 & 0 \\
\hline Chlaenius micans (Fabricius) & $\mathrm{C}$ & 0 & 1 & 0 & 17 & 0 & 0 \\
\hline Chlaenius naeviger Morawitz & $\mathrm{C}$ & 3 & 0 & 1 & 4 & 0 & 0 \\
\hline Chlaenius posticalis Motschulsky & $\mathrm{C}$ & 0 & 6 & 0 & 0 & 0 & 0 \\
\hline Lachnolebia cribricollis (Morawitz) & $\mathrm{C}$ & 0 & 1 & 0 & 0 & 0 & 0 \\
\hline Pheropsophus jessoensis Morawitz & $\mathrm{C}$ & 1 & 28 & 0 & 0 & 0 & 0 \\
\hline
\end{tabular}

ciliaris, and Trifolium repens with a 50\% ground cover, although the meadow edge ( $0-2 \mathrm{~m}$ from the edge) seemed to be mown less frequently, resulting in tall $(70-100 \mathrm{~cm})$, species-rich vegetation with $100 \%$ ground cover.

\section{Beetle sampling and classification}

To determine the edge responses of carabid beetles, five transects, stretching from $22.5 \mathrm{~m}$ in the interior of the meadow through the edge to $22.5 \mathrm{~m}$ in the interior of the secondary forest, were established at $3 \mathrm{~m}$ intervals within the $15 \mathrm{~m} \times 50 \mathrm{~m}$ quadrat (Fig. 1). Pitfall traps $(600 \mathrm{~mL}$ plastic bottles, internal diameter 9 $\mathrm{cm}$, height $12 \mathrm{~cm}$ ) were placed every $3 \mathrm{~m}$ along each transect $(16$ traps per transect, Fig. 1). To collect beetles, unbaited traps were set for $48 \mathrm{~h}$ without preservative in three seasons, early summer
(9-11 June, 2011), late summer (20-22 August, 2012) and midautumn (27-29 October, 2011). The mean daily air temperature on the seven consecutive days before the day of collection was $19.6^{\circ} \mathrm{C}$ in early summer, $27.3^{\circ} \mathrm{C}$ in late summer and $14.8^{\circ} \mathrm{C}$ in mid-autumn. Because transects were removed and newly established each season, the traps were not placed exactly in the same places every season (i.e., transects might be moved several meters from side to side from season to season).

Carabid beetles collected were identified to species and were classified into carnivores or granivores according to their feeding habit, based on Ishitani (1996). Because the feeding habits of Oxycentrus argutoroides (two individuals) are unknown, it was not assigned to feeding habit group. Among the carabid beetles

TABLE 2. Adjusted $\mathrm{R}^{2}$ and generalized cross-validation (GCV) scores of the two GAMs with and without interaction between the distance from the edge and season. The models with lower GCV scores and higher adjusted $\mathrm{R}^{2}$ are the better models.

\begin{tabular}{|c|c|c|c|c|c|c|}
\hline \multirow{3}{*}{ Category } & \multirow{3}{*}{$\mathrm{N}$} & \multicolumn{5}{|c|}{ Model comparison } \\
\hline & & \multicolumn{2}{|c|}{ With interaction } & \multicolumn{2}{|c|}{ Without interaction } & \multirow{2}{*}{$\begin{array}{l}\text { Significance of the difference } \\
\text { between the two models }\end{array}$} \\
\hline & & $\mathrm{R}_{\mathrm{adj}}^{2}$ & GCV & $\mathrm{R}_{\text {adj }}^{2}$ & GCV & \\
\hline Species richness & 240 & 0.391 & 1.443 & 0.253 & 1.671 & $P<0.001$ \\
\hline Total abundance & 240 & 0.374 & 0.689 & 0.234 & 0.807 & $P<0.001$ \\
\hline Carnivore abundance & 240 & 0.369 & 0.625 & 0.248 & 0.711 & $P<0.001$ \\
\hline Granivore abundance & 48 & 0.848 & 0.253 & 0.452 & 0.608 & $P<0.001$ \\
\hline Pt. microcephalus & 48 & 0.549 & 0.538 & 0.433 & 0.563 & $P=0.033$ \\
\hline Pt. planicollis & 48 & 0.890 & 0.297 & 0.818 & 0.332 & $P=0.032$ \\
\hline C. pallipes & 48 & 0.869 & 0.548 & 0.903 & 0.274 & $P=0.983$ \\
\hline
\end{tabular}




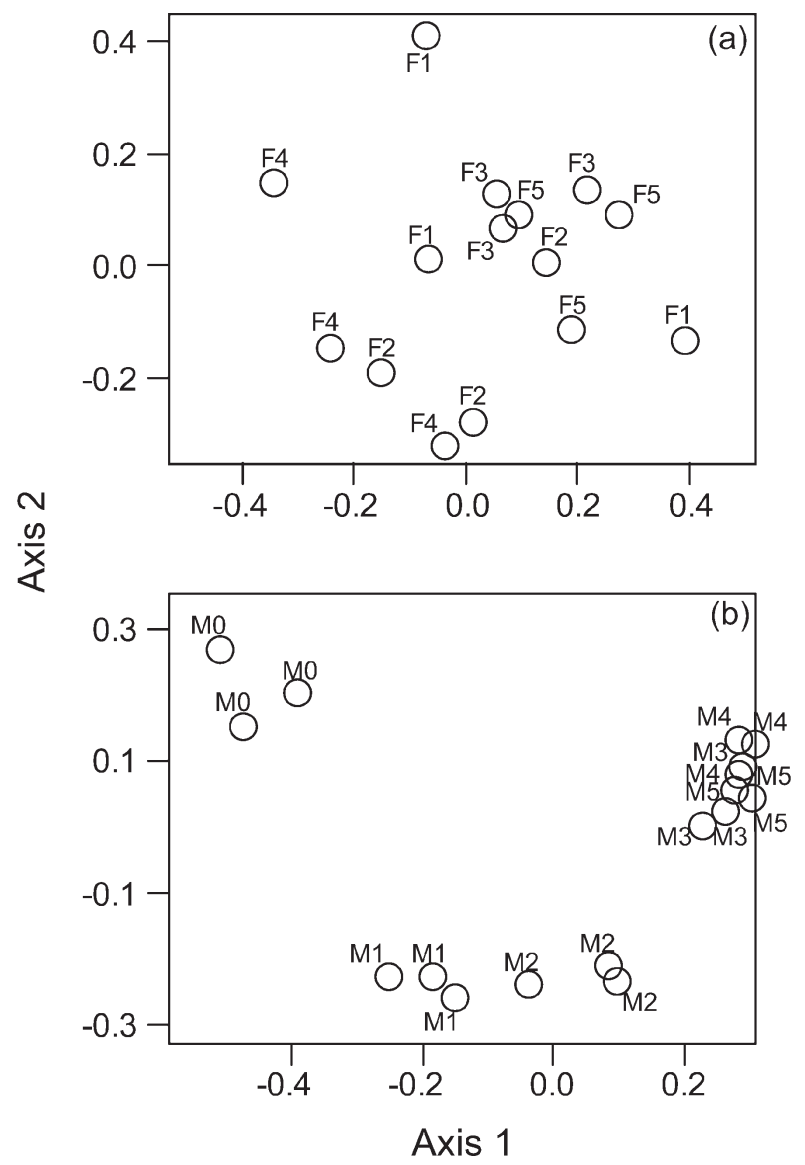

Fig. 2. Principal Coordinate Analysis (PCoA) ordinations showing differences in tree species composition in the forest (a) and herbaceous/grass species composition in the meadow (b). F1, F2, F3, F4 and F5 are located in the forest $0-5 \mathrm{~m}, 5-10 \mathrm{~m}, 10-15$ $\mathrm{m}, 15-20 \mathrm{~m}$ and 20-25 $\mathrm{m}$ from the edge, respectively. M0, M1, M2, M3, M4 and M5 are located in the meadow 0-2 m, 2-5 m, 5-10 $\mathrm{m}, 10-15 \mathrm{~m}, 15-20 \mathrm{~m}$ and $20-25 \mathrm{~m}$ from the edge, respectively.

collected, Amara chalcites is known to be a pest of radish (Mizukoshi, 2000). Carabid beetle nomenclature followed Ueno et al. (1985). The species collected are listed along with the number caught each season and their feeding habits in Table 1.

\section{Vegetation and soil surveys}

Vegetation was surveyed within the $15 \mathrm{~m} \times 50 \mathrm{~m}$ quadrat from 25 September to 2 October 2013. As mentioned above, because the traps were not set in the same places in each of the seasons, vegetation and soil surveys were not performed at each trapping point. Instead, these measurements were intended to reflect any general trend in environmental conditions across the forest edge. Vegetation surveys were performed by dividing the quadrat into thirty $5 \mathrm{~m} \times 5 \mathrm{~m}$ subquadrats. In the 15 forest subquadrats, all tree stems $\geq 2 \mathrm{~cm}$ in diameter at breast height (DBH) were identified to species and their DBH and height were measured. These stems were classified into shrub ( $\leq 6 \mathrm{~m}$ in height) or canopy ( $>6$ $\mathrm{m})$ layers. In the meadow subquadrats $(5-25 \mathrm{~m})$, five $1 \mathrm{~m} \times 1$ $\mathrm{m}$ grids were randomly placed in each subquadrat and species were identified and height and vegetation cover were measured in each grid. In the three meadow edge subquadrats $(0-5 \mathrm{~m})$, two grids were placed within $2 \mathrm{~m}$ of the edge and the other three between 2-5 $\mathrm{m}$ from the edge because the vegetation within $2 \mathrm{~m}$ of the edge seemed to be mown less frequently and apparently

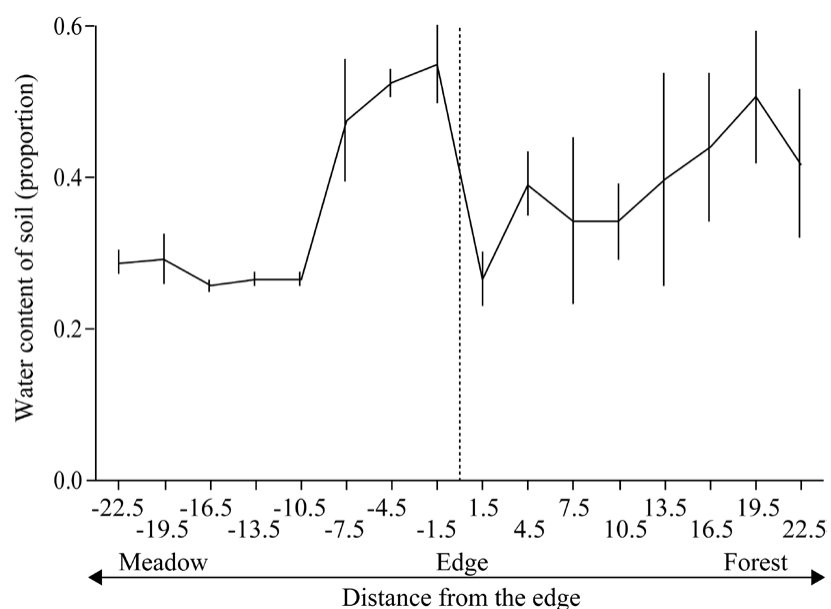

Fig. 3. Changes in the water content of the soil along the forestmeadow transect. The vertical bars show standard deviation of the water content of the soil expressed as a proportion.

different from that in the other parts of the meadow. In the forest subquadrats (containing five distance classes), the abundance of each species of tree was expressed as the number of stems in each subquadrat, whereas in the meadow subquadrats (containing six distance classes because of the separation of 0-2 $\mathrm{m}$ and 2-5 $\mathrm{m})$, the abundance of each species of plant was expressed as the proportion of grids in which it was present. The values for height and vegetation cover measured in $1 \mathrm{~m} \times 1 \mathrm{~m}$ grids were averaged for each subquadrat.

Soil samples were collected at the same 16 distance classes as pitfall traps on three lines ( $5 \mathrm{~m}$ apart) within the quadrat, using a 100-mL cylinder with both an internal diameter and a depth of $5 \mathrm{~cm}$. All soil samples were collected on 25 September 2013 and dried at $105^{\circ} \mathrm{C}$ for $24 \mathrm{~h}$ on the same day. Soil moisture was measured as a proportion (wet weight - dry weight) / (wet weight).

\section{Data analyses}

The relationships between soil moisture and plant species composition, and the distance from the edge, were determined using Pearson's correlation. These relationships were analyzed for the forest and meadow separately because the surveys and the compositions of the vegetation were not similar in the forest and meadow subquadrats. Because the number of soil moisture samples in each subquadrat was either one or two (e.g., for the subquadrats $10-15 \mathrm{~m}$ from the edge it was two and for those 5-10 $\mathrm{m}$ from the edge it was one; Fig. 1), soil moisture in a subquadrat with two soil samples was the mean of the two values. Plant species composition (trees in the forest and herbaceous plants/ grasses in the meadow) was expressed as scores along the first axis of a Principal Coordinate Analysis (PCoA) based on BrayCurtis similarity matrix using the "vegan" package (Oksanen et al., 2012).

The responses of beetles to the distance from the edge and seasonal differences were analyzed using generalized additive models (GAMs) by using the "mgev" package (Wood, 2011) in R ver. 2.15. We chose GAMs instead of GLMs because the responses of the beetles recorded along the forest-meadow transect were nonlinear. A thin plate regression spline and generalized cross validation $(\mathrm{GCV})$ were used to estimate the optimal amount of smoothing for the beetle responses (Zuur et al., 2009). For species richness, total abundance and abundance of carnivorous species, present in more than 20 traps in each season, per-trap species richness or abundance in each season were used as a response variable and the distance from the edge, season and their interac- 
Early summer

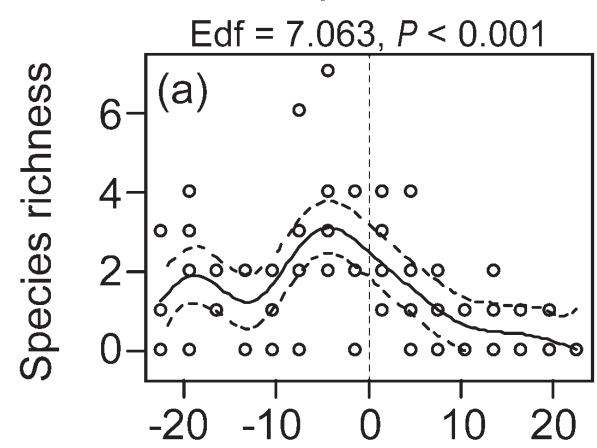

Edf $=6.704, P<0.001$

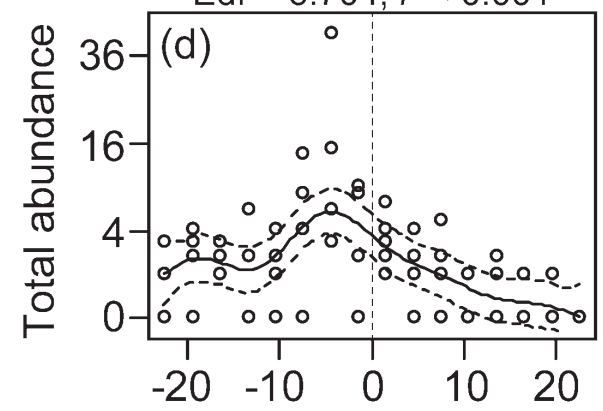

Edf $=6.717, P<0.001$

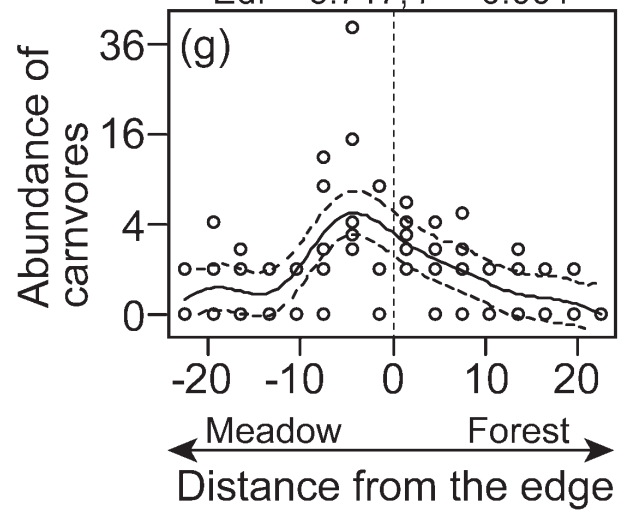

Late summer

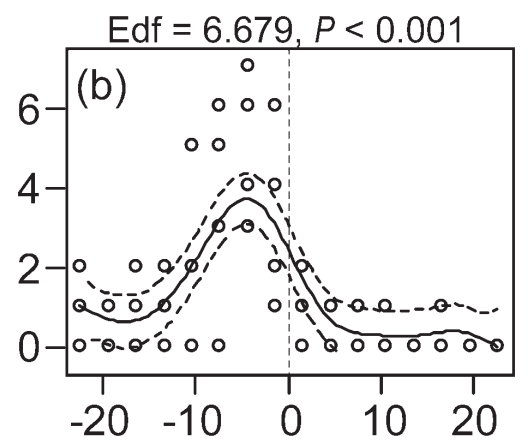

Edf $=6.426, P<0.001$

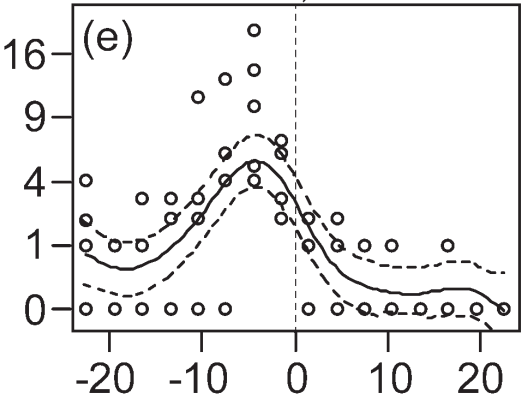

Edf $=6.560, P<0.001$

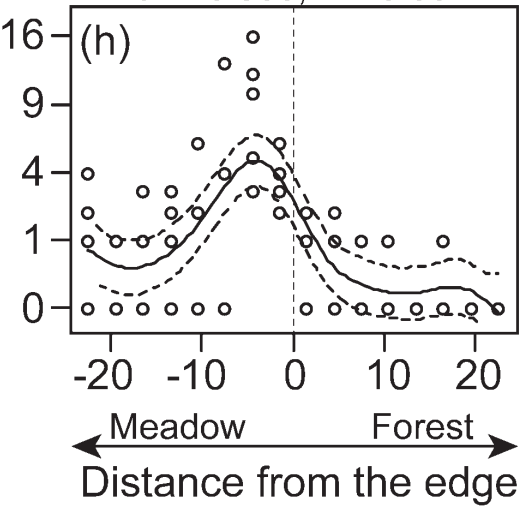

Mid-autumn

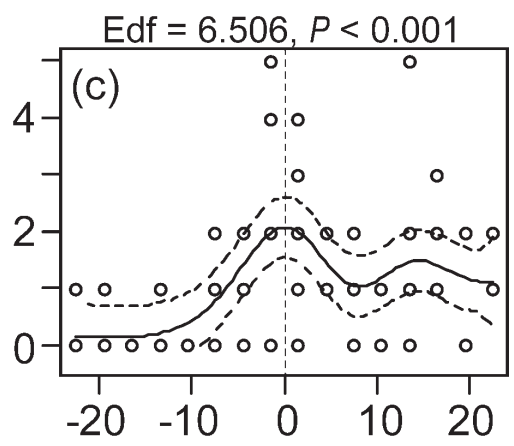

Edf $=4.657, P<0.001$

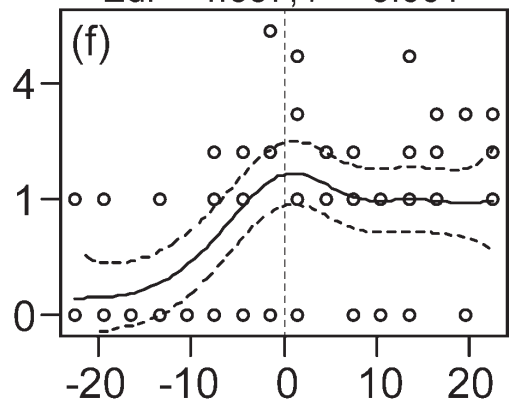

Edf $=4.144, P<0.001$

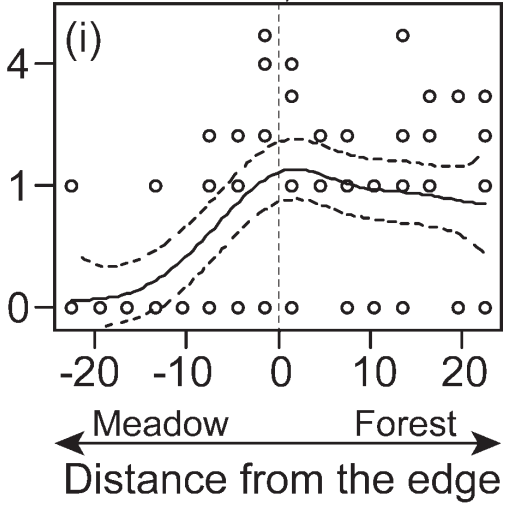

Fig. 4. Generalized additive models (solid lines: mean; dashed lines: $95 \%$ confidence intervals) of relationships between species richness $(\mathrm{a}-\mathrm{c})$, total abundance $(\mathrm{d}-\mathrm{f})$, and abundance of carnivores $(\mathrm{g}-\mathrm{i})$ per trap and the distance from the edge in the three seasons. Abundances were square-root transformed.

tion were used as explanatory variables. For the abundance of granivorous species and three species (Pterostichus microcephalus, Pterostichus planicollis and Chlaenius pallipes) that did not meet the above prerequisite despite being collected at more than four distance classes with $>10$ individuals in two or three seasons, the per-distance abundance (pooled abundance of the five traps in the same distance class) in each season was used as the response variable and distance from the edge, season and its interaction as explanatory variables. The significance of the interaction between the distance from the edge and season was tested by comparing the two models with and without the interaction using an F-test (Table 2). The splines and their significance and effective degrees of freedom (shown in Figs 4-5) were calculated separately for each season because significant interaction was detected in most cases (Table 2). For eight species (Pterostichus yoritomus, Pterostichus sulcitarsis, Dolichus halensis, Synuchus nitidus, Amara chalcites, Harpalus sinicus, Chlaenius micans, Pheropsophus jessoensis) that were present at more than four distances with $>10$ individuals and the results for all seasons were pooled or that mainly occurred only in one season, the relations between pooled abundance over all seasons and the distance from the edge were analyzed using GAMs, and significance and effective degrees of freedom for the splines were calculated for each species. In all GAMs, abundances were square-root transformed.

The species composition of the beetles caught in each trap was also analyzed using a PCoA based on Bray-Curtis similarity matrix for each season separately using the "vegan" package (Oksanen et al., 2012). The traps without beetles were omitted from the analyses.

\section{RESULTS}

Forest vegetation was slightly affected by the distance from the edge (Fig. 2a), whereas meadow vegetation changed continuously from the edge to $10 \mathrm{~m}$ into the interior associated with changes in soil moisture, whereas the vegetation in the interior of the dry meadow (10-25 m, Fig. 3 ) was quite similar (Fig. 2b). In the forest, there were only 


\section{Early summer}
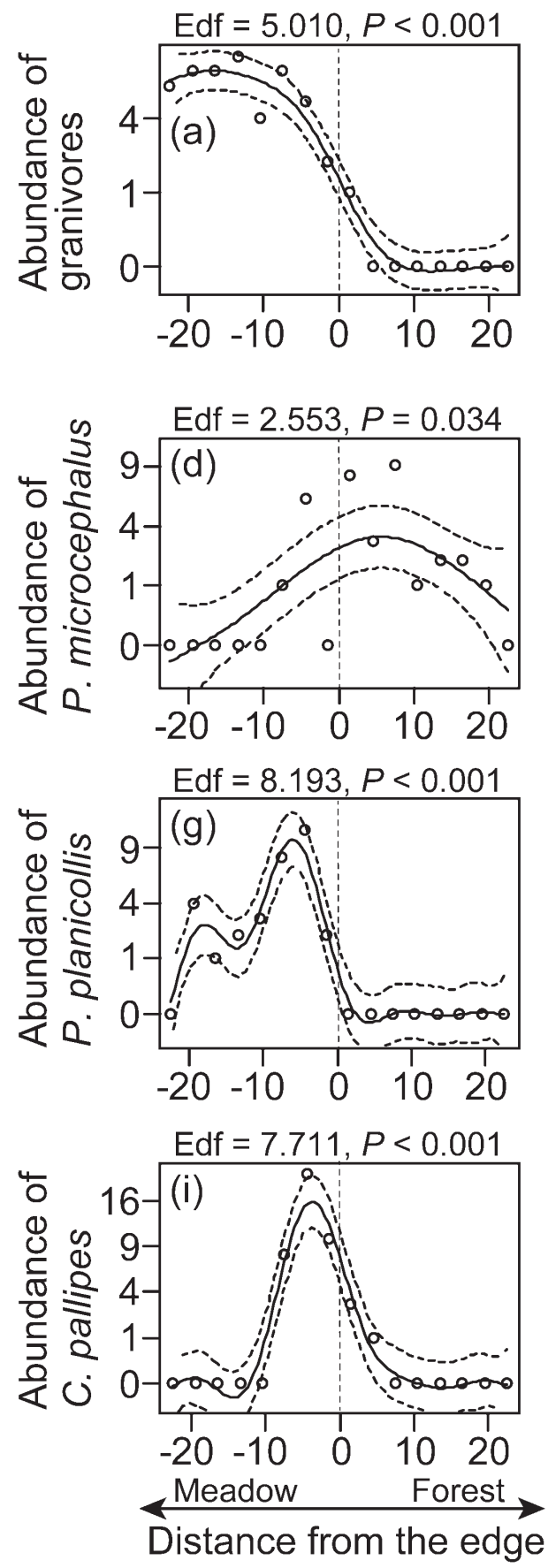

Late summer

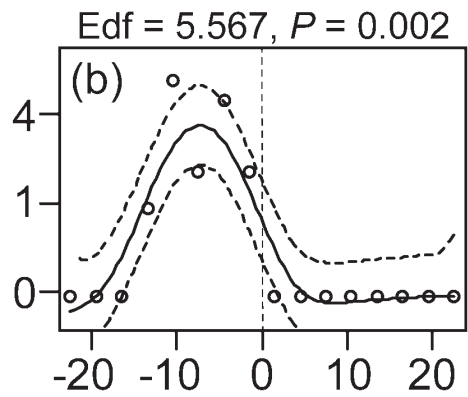

$\mathrm{Edf}=8.147 P<0.001$
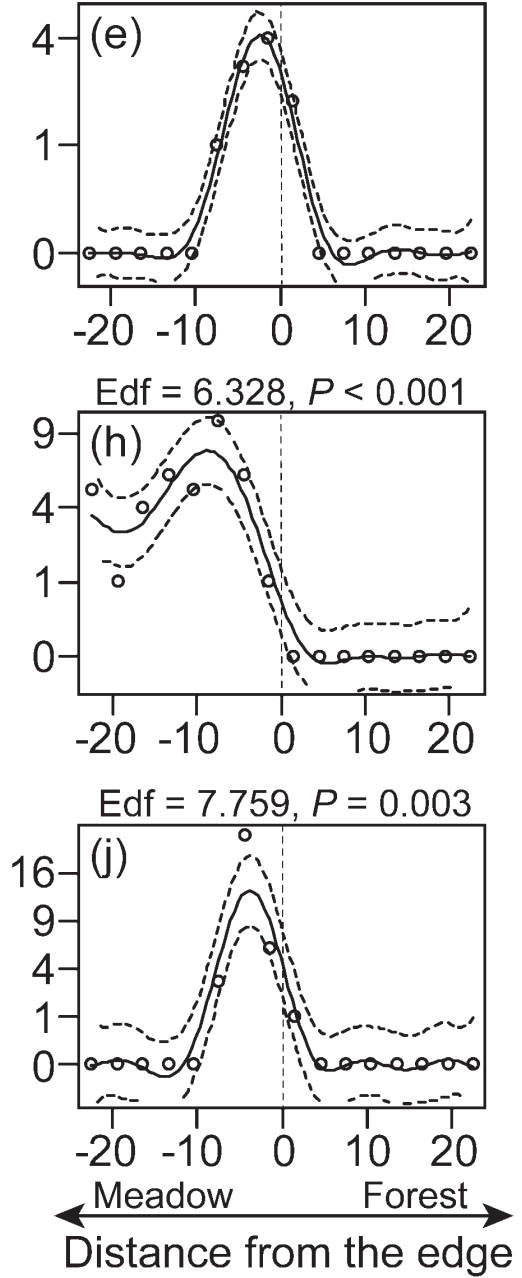

Mid-autumn
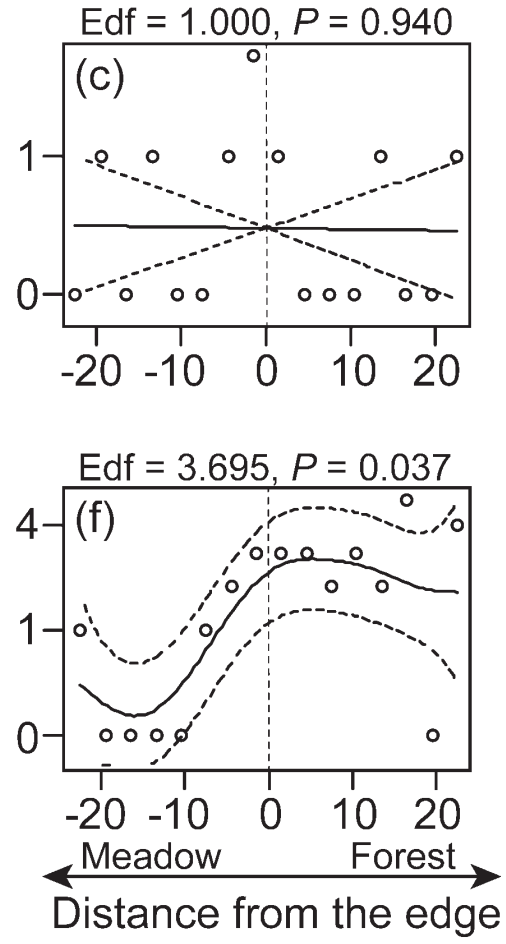

Fig. 5. Generalized additive models (solid lines: mean; dashed lines: $95 \%$ confidence intervals) of relationships between abundance of the granivores $(\mathrm{a}-\mathrm{c})$, Pt. microcephalus $(\mathrm{d}-\mathrm{f})$, Pt. planicollis $(\mathrm{g}, \mathrm{h})$ and C. pallipes $(\mathrm{i}, \mathrm{j})$ and the distance from the edge in the three seasons. Abundances of the five traps in each distance class were pooled and square-root transformed.

marginal correlations between stem density of the canopy layer and distance from the edge $(r=0.476, P=0.073, n=$ $15)$, and between stem density of the shrub layer and soil moisture $(r=-0.495, P=0.060, n=15)$. Tree species composition was not correlated with the distance from the edge $(r=-0.007, P=0.979, n=15)$, but was marginally correlated with soil moisture $(r=-0.497, P=0.059, n=15)$. In the meadow, vegetation cover was not correlated with the distance from the edge or soil moisture $(r<0.328, P$ $>0.184, n=18$, respectively), whereas plant species com- position was highly correlated with the distance from the edge $(r=-0.912, P<0.001, n=18)$ and soil moisture $(r=$ $-0.860, P=0.001, n=18)$. Soil moisture increased toward the edge of the meadow $(r=0.808, P<0.001, n=24)$ with a sharp increase at $7.5 \mathrm{~m}$ from the edge, whereas although very variable it gradually increased toward the interior of the forest ( $r=0.544, P=0.006, n=24)$ (Fig. 3).

In total, 448 individuals belonging to 34 species were collected, comprising 208 individuals belonging to 21 species in early summer (early June), 150 individuals be- 

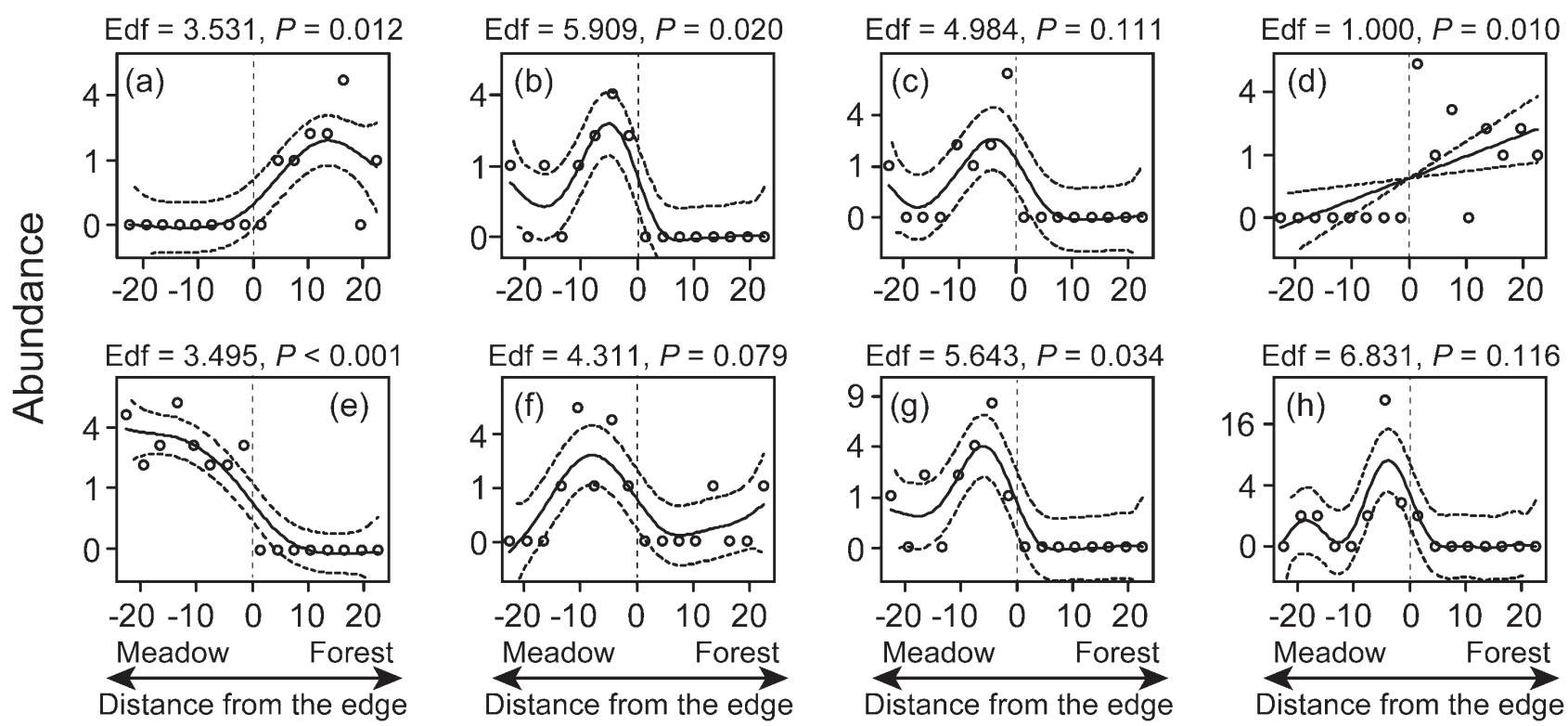

Fig. 6. Generalized additive models (solid lines: mean; dashed lines: $95 \%$ confidence intervals) of relationships between the pooled abundances of Pt. yoritomus (a), Pt. sulcitarsis (b), D. halensis (c), S. nitidus (d), Am. chalcites (e), H. sinicus (f), C. micans (g) and $P h$. jessoensis (h) and the distance from the edge. Abundances of the five traps in each distance class over all seasons were pooled and square-root transformed.

longing to 15 species in late summer (late August) and 90 individuals belonging to 22 species in mid-autumn (late October). Bray-Curtis similarities among seasons indicated that the beetle communities in early and late summer were similar (0.477), but that in mid-autumn differed from those in early summer (0.285) and late summer (0.269).

There were similar patterns in species richness, total abundance and abundance of carnivores recorded at different distances from the edge. In early and late summer, they peaked at $4.5 \mathrm{~m}$ into the meadow from the edge. However, species richness and abundance showed a steeper decrease across the edge in late summer (Fig. 4b, e, h) than in early summer (Fig. 4a, d, g) and remained at a low level in the forest interior in late summer. In mid-autumn, species richness and abundance increased starting in the meadow 10 $\mathrm{m}$ from the edge, peaked at the edge and was relatively constant in the forest (Fig. 4c, f, i). The interaction term between distance and season was significant for all of these cases (Table 2); i.e., the responses of species richness and abundances to the distance from the edge were significantly different among the seasons. In contrast, the abundance of granivores showed different responses. The abundance of granivores was high in the interior of the meadow in early summer, peaked $7.5 \mathrm{~m}$ into the meadow from the edge in late summer and was constant in mid-autumn (Fig. 5a-c). The interaction term was also significant (Table 2).

Seasonal differences in the responses to the edge were only determined for three species. The abundance of Pt. microcephalus was relatively high in the forest in early summer and mid-autumn, whereas it peaked in the meadow, just near the edge, in late summer (Fig. 5d-f). Although inclusion of the interaction term improved the model, the significance of the interaction was weak (Table 2). The distribution of Pt. planicollis was similar in early and late summer, with the peak in the meadow 4-8 $\mathrm{m}$ from the edge and no individuals in the forest (Fig. 5g-h). Inclusion of the interaction term slightly improved the model, and significance of the interaction was weak (Table 2). The distribution of $C$. pallipes was also similar in early and late summer, with the peak at 3-4 m into the meadow from the edge, and no individuals were caught more than $5 \mathrm{~m}$ into the interior of the forest (Fig. $5 \mathrm{i}-\mathrm{j}$ ). Inclusion of the interaction term did not improve the model and the interaction was not significant (Table 2). Of the eight species occurring in more than four distance classes with $>10$ individuals over all seasons, significant splines were obtained for five species. The distributions of six species clearly changed across the edge, with no individuals in either habitat (Fig. $6 \mathrm{a}, \mathrm{b}, \mathrm{c}, \mathrm{d}, \mathrm{e}, \mathrm{g})$.

The species compositions of the carabid beetles were largely separated between forest and meadow in all seasons (Fig. 7). However, this separation was less clear in mid-autumn (Fig. 7c), and species composition of the trap catches around the edge tended to be similar to those recorded in other habitats in early and late summer (Fig. 7a, b).

\section{DISCUSSION}

This study clearly showed that distributions of species richness and abundance of ground beetles along a forestmeadow transect differed between seasons. The reasons for the seasonal differences were (1) species occurring in two or more seasons, e.g., Pt. microcephalus, responded to the forest edge differently in different seasons, and (2) species responding differently to the forest edge are active in different seasons and consequently, species richness and abundance at the forest edge differed in different seasons; e.g., two species with different edge responses, Am. chalcites and $H$. sinicus, are active at different times of year (the former in early summer and latter mainly in the late summer). 

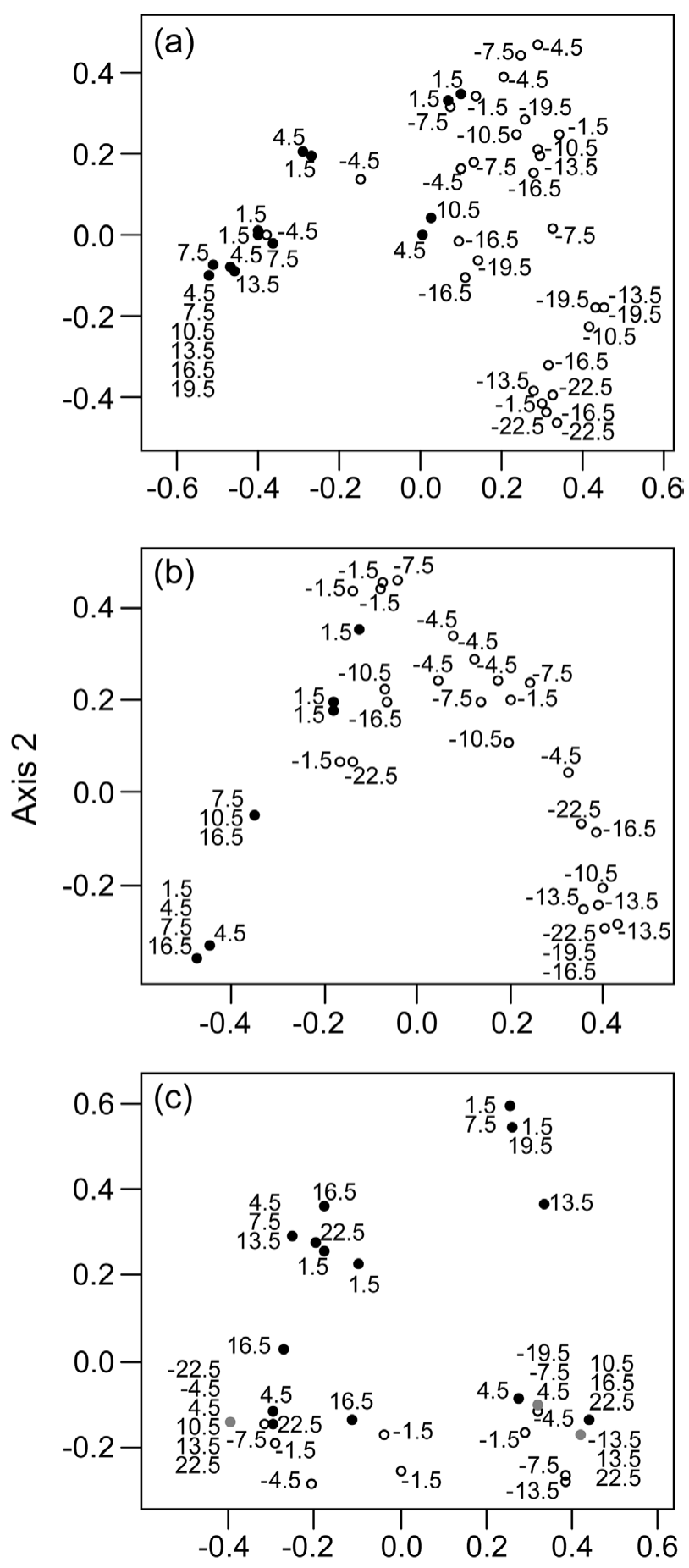

Axis 1

Fig. 7. Principal Coordinate Analysis (PCoA) ordinations showing the differences in beetle species composition of the pitfall trap catches recorded in early summer (a), late summer (b) and mid-autumn (c). Traps that did not catch beetles were not included in the analyses. Solid circles: traps in the forest, open circles: traps in the meadow, grey circles: traps both in the forest and the meadow with identical species composition.

Contrary to our expectation that species richness and abundance of carabid beetles would peak in the forest near the edge in hot late summer and in the meadow near the edge in early summer and mid-autumn, both peaked in the meadow near the edge (with the peak at $4.5 \mathrm{~m}$ into the meadow from the edge) with a low values for both these parameters in the forest in late summer, whereas they peaked at the edge in mid-autumn (Fig. 4a-f). This indicates that species preferring open land did not move into the forest in summer and that forest species did not move into the meadow in mid-autumn. Species-level analyses showed that none of the three species that were captured in two or three seasons moved into the forest more frequently in late summer than early summer and autumn (Fig. 4d-j), but that more individuals of Pt. microcephalus and $C$. pallipes stayed in the meadow in late summer than in the cooler seasons. They can avoid high temperatures in the meadow during the day in summer because most carabid species are nocturnal (Kegel, 1990; Lövei \& Sunderland, 1996) and stay in the soil during the day. The increase in the numbers of Pt. microcephalus and $H$. sinicus caught in the forest from late summer to mid-autumn (Figs 5d-f, 6f, Table 1) indicates they hibernate in the forest. Some carabids are known to hibernate in secondary forests and other wooded vegetation, such as hedges (Sutherton, 1985; Lövei \& Sunderland, 1996). It should be noted that if the samples collected in different seasons are pooled, they might be regarded as generalist species. However, the seasonal changes in micro-distribution near the edge indicate that they were not generalists but require both forest and open land.

Furthermore, species-level analyses detected the presence of species preferring the meadow near the edge (Figs 5,6 ), as well as species occurring either in the forest (e.g., Pt. yoritomus and S. nitidus) or the meadow (e.g., Pt. planicollis and Am. chalcites). The species occurring only in the forest or meadow did not cross the edge into the other habitat, suggesting that the forest edge acted as a barrier for these species. In addition, there can be several reasons why many species prefered the meadow near the edge. First, near the edge (1.5-7.5 $\mathrm{m}$ into the meadow from the edge) the soil in the meadow was moister and the ground softer than in the interior of the meadow (Fig. 3) and therefore these species might merely prefer a humid open environment with soft soil. Second, some species might prefer open land in riparian areas, where various types of vegetation, such as riparian forests, areas of shrubs and grassland, are naturally arranged in a mosaic manner in relation to the differences in geomorphic surface and disturbance (Nakamura et al., 2007). Because open land usually adjoin forests or shruby areas in riparian areas, forest edges in agricultural landscapes may provide a similar habitat for these species. Among the carabid beetles collected, Archipatrobus flavipes and $C$. pallipes are regarded as species inhabiting riparian open vegetation (Ishitani, 1996). Finally, as several studies have shown (Magura et al., 2001; Magura, 2002; Lövei et al., 2006), there are some edge species. Kagawa \& Maeto (2009) report that the higher prey abundance around the edges than in the interior of forests results in the higher abundance of the large carabid species, Carabus yaconius Bates, at the edges of forests. Further studies of beetle distributions along forest-open land transects that vary little in soil moisture and in other types of vegetation, such as ri- 
parian areas, are needed in order to reveal the habitat preferences or original habitats of these species. As indicated in other studies (Kotze \& Samways, 1999; Magura, 2002; Lövei et al., 2006; Ewers \& Didham, 2008; Roume et al., 2011), however, a mixture of species with different habitat requirements enhanced the species richness and abundance of ground beetle around the edge of the forest.

Semi-natural vegetation such as grassland and secondary forest are important sources of crop pollinators (Kremen et al., 2002; Chacoff \& Aizen, 2006, Taki et al., 2010) and pest control agents (Marino \& Landis, 1996; Thies \& Tscharntke, 1999; Landis et al., 2000). Because the open vegetation studied was not a crop but a fertilized meadow, our results may not be relevant to whether pests are controlled by predators that come from adjacent forests. However, this study indicates that secondary forests can provide important hibernation sites for some species. Roume et al. (2011) point out that the extent of the movement of forest species into various crops and grassland is very variable ranging from a few meters to a few dozens of meters even at high-contrast edges, and conclude that this variability may be attributed to the heterogeneity of the vegetation and differences in the management of open habitats. In addition, in areas where it is unlikely pests are controlled by forest or edge species it is possible that pests are controlled mainly by species preferring open land. Because most species preferring open land hibernate in fallow fields and field boundaries (Sutherton, 1985; Yamazaki et al., 2003; Frank \& Reichhart, 2004; MacLeod et al., 2004), the management of fields and field boundaries, as well as the spatial arrangement of secondary forests, is important if one wishes to increase the abundance of carnivorous and granivorous beetles. Yamazaki et al. (2003) records a decrease in populations of overwintering beneficial beetles with vegetation succession in 0.5 - to 3 -year-old fallow vegetable fields in Japan, whereas Frank \& Reichhart (2004) record the opposite trend in wheat fields and 1- to 3 -year-old fallow fields in Switzerland, indicating the need for surveys in regions with different environmental and climatic conditions. Further studies are needed on the distances predatory forest or edge species move into various types of crops so that pest and weed control in agricultural landscapes can be enhanced. It is also important not only to determine the contribution of carabids to controlling pests and weeds but also that of other beneficial arthropods, such as spiders and parasitoids and their seasonal occurrence in crops and other vegetation in agricultural landscapes.

ACKNOWLEDGEMENTS. We are grateful to the land owners for allowing us to do this research and providing the information on the management of the meadow. This study was performed as a field exercise for the program, "Creating local, active human resources and fostering institutions", funded by Japan Science and Technology Agency. We also thank the people who participated in this program.

\section{REFERENCES}

Barbosa O. \& Marquet P.A. 2002: Effects of forest fragmentation on the beetle assemblage at the relict forest of Fray Jorge, Chile. _ Oecologia 132: 296-306.
Benton T.G., VickerY J.A. \& WiLSON J.D. 2003: Farmland biodiversity: is habitat heterogeneity the key? - Trends Ecol. Evol. 18: $182-188$.

Bergman K., Askling J., Ekberg O., Ignell H., Wahlman H. \& Milberg P. 2004: Landscape effects on butterfly assemblages in an agricultural region. - Ecography 27: 619-628.

Chacoff N.P. \& Aizen M.A. 2006: Edge effects on flower-visiting insects in grapefruit plantations bordering premontane subtropical forest. - J. Appl. Ecol. 43: 18-27.

Ewers R.M. \& Didham R.K. 2008: Pervasive impact of largescale edge effects on a beetle community. - PNAS 105: 54265429

Falcucci A., Maiorano L. \& Boitani L. 2007: Changes in landuse/land-cover patterns in Italy and their implications for biodiversity conservation. - Landsc. Ecol. 22: 617-631.

Frank T. \& Reichhart B. 2004: Staphylinidae and Carabidae overwintering in wheat and sown wildflower areas of different age. - Bull. Entomol. Res. 94: 209-217.

French B.W., Elliott N.C., Berberet R.C. \& Burd J.D. 2001: Effects of riparian and grassland Habitats on ground beetle (Coleoptera: Carabidae) assemblages in adjacent wheat fields. - Environ. Entomol. 30: 225-234.

HoneK A. 1997: The effect of temperature on the activity of Carabidae (Coleoptera) in a fallow field. - Eur. J. Entomol. 94: 97-104.

Honek A., Martinkova Z., Saska P. \& Pekar S. 2007: Size and taxonomic constraints determine the seed preferences of Carabidae (Coleoptera). - Basic Appl. Ecol. 8: 343-353.

Ichihara M., Maruyama K., Yamashita M., SaWAda H., InAGaki H., Ishida Y. \& Asai M. 2011: Quantifying the ecosystem service of non-native weed seed predation provided by invertebrates and vertebrates in upland wheat fields converted from paddy fields. - Agric. Ecosyst. Environ. 140: 191-198.

IDE J. 2002: Mating behaviour and light conditions cause seasonal changes in the dispersal pattern of the satyrine butterfly Lethe diana. - Ecol. Entomol. 27: 33-40.

IsHiTANI M. 1996: Ecological studies on ground beetles (Coleoptera: Carabidae, Brachinidae) as environmental indicators. - Mis. Rep. Hiwa Mus. Natl. Hist. 34: 1-110 [in Japanese, English abstr.].

Kagawa Y. \& Maeto K. 2009: Spatial population structure of the predatory ground beetle Carabus yacomnus (Coleoptera: Carabidae) in the mixed farmland-woodland satoyama landscape of Japan. - Eur. J. Entomol. 106: 385-391.

KATO M. 2001: "SATOYAMA" and biodiversity conservation: "SATOYAMA" as important insect habitats. - Glob. Environ. Res. 5: 135-149.

Kegel B. 1990: Diurnal activity of carabid beetles living on arable land. In Stork N.E. (ed.): The Role of Ground Beetles in Ecological and Environmental Studies. Intercept, Andover, pp. 65-76.

Kim J.-E., Hong S.-K. \& NaKagoshi N. 2006: Changes in patch mosaics and vegetation structure of rural forested landscapes under shifting human impacts in South Korea. _ Landsc. Ecol. Eng. 2: 177-195.

Kotze D.J. \& Samways M.J. 1999: Invertebrate conservation at the interface between the grassland matrix and natural Afromontane forest fragments. - Biodiv. Conserv. 8: 1339-1363.

Kremen C., Williams N.M. \& Thorp R.W. 2002: Crop pollination from native bees at risk from agricultural intensification. PNAS 99: 16812-16816.

Kremen C., Williams N.M., Bugg R.L., Fay J.P. \& Thorp R.W. 2004: The area requirements of an ecosystem service: crop pollination by native bee communities in California. - Ecol. Lett. 11: 1109-1119. 
KRomP B. 1999: Carabid beetles in sustainable agriculture: a review on pest control efficacy, cultivation impacts and enhancement. - Agric. Ecosyst. Environ. 74: 187-228.

Landis D.A., Wratten S.D. \& GurR G.M. 2000: Habitat management to conserve natural enemies of arthropod pests in agriculture. - Annu. Rev. Entomol. 45: 175-201.

LÖVEI G.L. \& SunderLAND K.D. 1996: Ecology and behavior of ground beetles (Coleoptera: Carabidae). - Annu. Rev. Entomol. 41: 231-256.

Löver G.L., Magura T., Tóthmérész B. \& KöDöBöcz V. 2006: The influence of matrix and edges on species richness patterns of ground beetles (Coleoptera: Carabidae) in habitat islands. Glob. Ecol. Biogeogr. 15: 283-289.

MacLeod A., Wratten S.D., Sotherton N.W. \& Thomas M.B. 2004: 'Beetle banks' as refuges for beneficial arthropods in farmland: long-term changes in predator communities and habitat. - Agric. For. Entomol. 41: 147-154.

Magura T. 2002: Carabids and forest edge: spatial pattern and edge effect. - For. Ecol. Manag. 157: 23-37.

Magura T., Tóthmérész B. \& Molnár T. 2001: Forest edge and diversity: carabids along forest-grassland transects. - Biodiv. Conserv. 10: 287-300.

Marino P.C. \& LANDis D.A. 1996: Effect of landscape structure on parasitoid diversity and parasitism in agroecosystems. Ecol. Appl. 6: 276-284.

MatLACK G.R. 1993: Microenvironment variation within and among forest edge sites in the eastern United States. - Biol. Conserv. 66: 185-194.

MizuKoshi T. 2000: Damage of carabid beetles to spring seeding radish in central Oshima, Hokkaido. IV. Toxic effect of four foliar spray insecticides againsg three species of carabid beetle adults. - Annu. Rep. Plant Prot. North Japan 51: 227-230 [in Japanese].

MurCIA C. 1995: Edge effects in fragmented forests: implications for conservation. - Trends Ecol. Evol. 10: 58-62.

Nakamura F., Shin N. \& Inahara S. 2007: Shifting mosaic in maintaining diversity of floodplain tree species in the northern temperate zone of Japan. — For. Ecol. Manag. 241: 28-38.

OHSAKI N. 1986: Body temperatures and behavioural thermoregulation strategies of three Pieris butterflies in relation to solar radiation. - J. Ethol. 4: 1-9.

Oksanen J., Blanchet F.G., Kindt R., Legendre P., Minchin P.R., O’Hara R.B., Simpson G.L., Solymos P., Stevens M.H. \& Wagner H. 2012: Vegan: Community Ecology Package. $R$ Package Version 2.0-5. Retrieved from http://CRAN.R-profect.org/package $=$ vegan
Rand T.A., Tylianakis J.M. \& TscharntKe T. 2006: Spillover edge effects: the dispersal of agriculturally subsidized insect natural enemies into adjacent natural habitats. - Ecol. Lett. 9: 603-614.

Ries L. \& SisK T.D. 2004: A predictive model of edge effects. Ecology 85: 2917-2926.

Ries L., Whittaker R.J., Battin J. \& SisK T.D. 2004: Ecological responses to habitat edges: mechanisms, models, and variability explained. - Annu. Rev. Ecol. Evol. Syst. 35: 491-522.

Roume A., Deconchat M., Raison L., Balent G. \& Ouin A. 2011: Edge effects on ground beetles at the woodlot-field interface are short-range and asymmetrical. - Agric. For. Entomol. 13: 395-403.

SotHERTON N.W. 1985: The distribution and abundance of predatory Coleoptera overwintering in field boundaries. - Ann. Appl. Biol. 106: 17-21.

Taki H., Okabe K., Yamaura Y., Matsuura T., Sueyoshi M., MAKINO S. \& MAETo K. 2010: Effects of landscape metrics on Apis and non-Apis pollinators and seed set in common buckwheat. - Basic Appl. Ecol. 11: 594-602.

Thies C. \& TsCharntKe T. 1999: Landscape structure and biological control in agroecosystems. - Science 285: 893-895.

Ueno S., Kurosawa Y. \& Sato M. 1985: The Coleoptera of Japan in Color. Vol. 2. Hoikusha, Osaka, 514 pp. [in Japanese].

van Halder I., Barbaro L. \& Jactel H. 2011: Conserving butterflies in fragmented plantation forests: are edge and interior habitats equally important? - J. Insect Conserv. 15: 591-601.

Weibull A., Bengtsson J. \& Nohlgren E. 2000: Diversity of butterflies in the agricultural landscape: the role of farming system and landscape heterogeneity. - Ecography 23: 743-750.

Wood S.N. 2011: Fast stable restricted maximum likelihood and marginal likelihood estimation of semiparametric generalized linear models. - J. R. Stat. Soc. (B) 73: 3-36.

YAMASHITA N. 2011: Weed seed predation by invertebrates and its availability for weed management. - J. Weed Sci. Tech. 56: 182-190 [in Japanese, English abstr.].

Yamazaki K., Sugiura S. \& Kawamura K. 2003: Ground beetles (Coleoptera: Carabidae) and other insect predators overwintering in arable and fallow fields in central Japan. - Appl. Entomol. Zool. 38: 449-459.

Young A. \& Mitchell N. 1994: Microclimate and vegetation edge effects in a fragmented podocarp-broadleaf forest in New Zealand. - Biol. Conserv. 67: 63-72.

Zuur A.F., Ieno E.N., Walker N.J., Saveliev A.A. \& Smith G.M. 2009: Mixed Effects Models and Extensions in Ecology with R. Springer, New York, 574 pp.

Received June 30, 2014; revised and accepted October 25, 2014 Prepublished online December 1, 2014 